4 Ruiz J, Blanche H, James RE, et al. Gln-Arg 192 polymorphism of paraoxonase and coronary heart disease in type 2 diabetes. Lancet 1995; 346: $869-72$.

5 Odawara M, Matsunuma A, Yamashita $K$. Platelet glycoprotein IIIaPI ${ }^{\mathrm{A}}$ polymorphism and Japanese diabetic patients with coronary heart disease. Lancet 1996; 348: 1310.

\section{Carbon monoxide poisoning}

\section{Sir,}

The recent review of carbon monoxide poisoning by Balzan et $a l^{1}$ provided helpful advice about this sometimes difficult diagnosis. We would, however, hesitate to follow the recommendations made about the treatment of $\mathrm{CO}$ poisoning. Their assessment of the benefit of hyperbaric oxygen (HBO) does not appear to be based on the presented evidence and the potential complications of transporting critically ill patients to $\mathrm{HBO}$ facilities do not receive the attention they merit.

The authors cite one randomised trial assessing $\mathrm{HBO}$ in patients who were not pregnant. $^{2}$ The indications they propose for $\mathrm{HBO}$ include two (impaired consciousness and cardiovascular instability) that were the exclusion criteria in this trial. Case series are also cited. ${ }^{3,4}$ We do not believe these provide sufficient information to allow clinically useful comparison between different treatments. Their rôle is to generate rather than to test hypotheses. We conclude with the observation of Thom et al (our italics) ${ }^{2}$; "Questions that should be addressed include whether treating patients [with hyperbaric oxygen] more than 6 hours after poisoning is effective and whether the benefits outweigh the costs of transportation and treatment."

RD HARDERN AJ GRAY

Accident and Emergency Department, St. Fames's University Hospital, Leeds, UK

1 Balzan MV, Agius G, Debono AG. Carbon monoxide poisoning: easy to treat but difficult to recognise. Postgrad Med ₹ 1996; 72: 470-3.

2 Thom SR, Taber RI, Mendiguren II, Clark JM, Hardy KR, Fisher AB. Delayed neuropsychologic sequelae after carbon monoxide poisoning: gic sequelae after carbon monoxide poisoning: prevention by treatment with hyperbarit

Ann Emerg Med 1995; 25: 474-80.
3 Myers RAM, Snyder SK, Lindberg S, Cowley RA. Value of hyperbaric oxygen in suspected carbon monoxide poisoning. $\mathscr{f} A M A$ 1981; 246: 2478-80.

4 Norkool DM, Kirkpatrick JN. Treatment of acute carbon monoxide poisoning with hyperbaric oxygen: a review of 115 cases. Ann Emerg Med 1985; 14: $1168-71$.

This letter was shown to the authors, who responded as follows:

\section{Sir,}

In our article we attempted to reproduce widely accepted recommendations in the current literature for the use of $\mathrm{HBO}$ in $\mathrm{CO}$ poisoning. These are based mainly on clinical experience and retrospective case series comparing outcomes in patients treated with $\mathrm{HBO}$ with historical controls receiving normobaric oxygen (NBO). These have shown clear-cut, often dramatic improvements with $\mathrm{HBO}$ in severely intoxicated patients.

I agree with Hardern et al that, in principle, any therapeutic measure and its indications should be tested in a large prospective randomised controlled trial. However, in view of the evidence in retrospective case series for the greater effectiveness of $\mathrm{HBO}$, it is unlikely that any ethical committee would permit such a trial in severe CO intoxication. It is also unlikely that a properly informed patient or his delegate would give his consent to participate in such a trial.

Probably for these reasons, two recent prospective randomised controlled trials comparing $\mathrm{HBO}$ with NBO have excluded patients with severe poisoning (those with loss of consciousness or myocardial instability) and concentrated on moderate intoxication. Both these studies have confirmed the utility of HBO, compared to NBO, in accelerating recovery and preventing delayed neurological sequelae. ${ }^{1,2}$

However, does it make sense in clinical practice to treat moderately intoxicated cases with $\mathrm{HBO}$ and not severe cases for the simple reason that a trial cannot be performed as treatment is considered potentially life-saving? Would such a position be tenable in a court of law? Is it logical to treat moderately intoxicated women, except when they carry a foetus very vulnerable to hypoxia, when it has been shown that HBO is safe in pregnancy?

As regards the transport of critically ill patients, it is accepted that supportive care must never be compromised in transport and that the logistics of every case must be considered individually and carefully evaluated in a local context. However I feel strongly that, in line with guidelines in the literature, comatose patients, or patients with prolonged loss of consciousness should, whenever possible, be offered $\mathrm{HBO}$.

HBO treatment in patients presenting late is still debatable. Whether the cost of an $\mathrm{HBO}$ unit or the transport expenses are justified or not by the benefit of therapy depends on the logistics and health rationing priorities of different healthcare setups.

MV BALZAN

Department of Medicine St Luke's Hospital,

Guardamangia, Malta

1 Thom SR, Taber RL, Mendiguren II, Clark JM Hardy KR, Fisher AB. Delayed neurophysica sequelae after carbon monoxide poisoning: prevention by treatment with hyperbaric oxygen Ann Emerg Med 1995; 25: 474-80.

2 Dugasse JL, Izard PH, Celsis P, et al. Moderate carbon monoxide poisoning: hyperbaric or normobaric oxygen? In: Baker DJ, Schmutz J, eds. Proceedings of the 2nd Swiss Symposium on hyperbaric medicine 1990; pp 289-97.

\section{Heart failure in the elderly}

Sir

Although I enjoyed reading the well-researched review of the management of heart failure in the elderly, ${ }^{1}$ I disagree with the emphatic restatement of the conventional view that adjunctive treatment with spironolactone is absolutely contraindicated in patients already co-prescribed angiotensinconverting enzyme (ACE) inhibitors and loop diuretics. The reality is that amongs patients already co-prescribed ACE-inhibitors and loop diuretics, there will always be a few with refractory, and potentially lifethreatening hypokalaemia, due, in some instances, to hyperaldosteronism, ${ }^{2}$ for which corrective treatment could either be resection of an adrenocortical adenoma or co-prescription of spironolactone and ACE-inhibitors. ${ }^{2}$

In my own register, dating back to 1984 comprising 349 patients co-prescribed ACEinhibitors and loop diuretics for heart failure, three women, now aged 81,81 and 79 , respectively, had coexisting hypertension and hypokalaemia, the latter refractory to ACEinhibitors. In the first patient, with a nadir serum potassium of $2.7 \mathrm{mmol} / \mathrm{l}$, following co- prescription of spironolactone $25 \mathrm{mg} /$ day, frusemide $40-80 \mathrm{mg} /$ day and enalapril $10 \mathrm{mg} /$ day followed by lisinopril $20 \mathrm{mg} /$ day, the serum potassium was maintained in the range $3.9-4.4 \mathrm{mmol} / \mathrm{l}$ during the last six months of a 30-month period of 'triple' therapy. Prior to commencement of 'triple' therapy, her 24-hour urinary aldosterone was $7 \mathrm{nmol}$ (reference range 10-50) in $1050 \mathrm{ml}$ urine, and her $09.00 \mathrm{~h}$ serum cortisol was $516 \mathrm{nmol} / \mathrm{l}$.

In the second patient, the co-prescription of spironolactone was precipitated by a fall in serum potassium to $2.2 \mathrm{nmol} / 1$ whilst taking enalapril $20 \mathrm{mg} /$ day and frusemide $80 \mathrm{mg}$ / day. Her 24-hour urinary aldosterone output was $25 \mathrm{nmol}$ (in $1620 \mathrm{ml}$ urine), but neither 24-hour urinary cortisols nor serum cortisols were requested due to the (?erroneous) perception that a serum potassium of $2.6 \mathrm{mmol} / \mathrm{l}$, 11 years previously, rendered the diagnosis of Cushing's syndrome unlikely in the absence of the development of clinical stigmata over that period. Ultrasonography had also not identified any adrenal abnormality. This patient was subsequently prescribed spironolactone $25 \mathrm{mg} /$ day, in addition to frusemide $80 \mathrm{mg}$ day, and enalapril was increased to $40 \mathrm{mg} / \mathrm{day}$; 28 months later her serum potassium had increased to $3.2 \mathrm{nmol} / \mathrm{l}$.

The third patient had an initial blood pressure of $280 / 100 \mathrm{mmHg}$ in association with plasma potassium of $2.9 \mathrm{nmol} / 1$, urea of $16.5 \mathrm{mmol} / \mathrm{l}$, creatinine of $139 \mu \mathrm{mol} / \mathrm{l}$ and body weight of $47 \mathrm{~kg}$. Unfortunately, her 24-hour urinary aldosterone and cortisol levels were quantified when she was already taking spironolactone $50 \mathrm{mg} /$ day, frusemide $120 \mathrm{mg} /$ day, ramipril $10 \mathrm{mg} /$ day, and lacidipine $4 \mathrm{mg} /$ day, yielding values of $2.0 \mathrm{nmol}$ and $71 \mathrm{nmol}$, respectively, in $800 \mathrm{ml}$ urine. Computed tomography showed that she had right-sided hydronephrosis, but no adrenal adenoma. During the subsequent three months, spironolactone was progressively increased to $200 \mathrm{mg} /$ day, frusemide reduced to $80 \mathrm{mg} / \mathrm{day}$, whilst ramipril was maintained at $10 \mathrm{mg} /$ day and lacidipine increased to $6 \mathrm{mg} /$ day. Consequently, her blood pressure fell to $200 / 90 \mathrm{mmHg}$, but her plasma potassium remained at $2.9 \mathrm{mmol} / 1$, with urea $17.1 \mathrm{mmol} / 1$ and creatinine $130 \mu \mathrm{mol} / \mathrm{l}$. Due to the subsequent development of a pruritic maculopapular rash, losartan $50 \mathrm{mg}$ bid was substituted for ramipril, and she is now undergoing titration of the spironolactone dose, due to a $75 \%$ reduction in frusemide requirements (based on transient development of reversible prerenal uraemia).

OMP JOLOBE

Tameside General Hospital, Ashton-under-Lyne, Lancashire OL6 9RW, UK

1 King D. Diagnosis and management of heart failure in the elderly. Postgrad Med F 1996: 72: 577-80.

2 Geist M, Dorian P, Davies T, et al. Hyperaldosteronism and sudden cardiac death. Am $\mathcal{F}$ Cardio 1996: 78: $605-6$.

This letter was shown to the author, who responded as follows:

Sir,

I make no apology for stating that the use of spironolactone (and other potassium-conserving diuretics), in conjunction with ACEinhibitors should be discouraged in the elderly. This combination in older people 